\title{
A Higher Percentage of Elderly on Dulaglutide Achieved HbA1c $<7.5 \%$ Without Nocturnal Hypoglycemia vs. Glargine in AWARD-2
}

Luis-Emilio García-Pérez, Maria Yu, Pamela W. Anderson, Vivian T. Thieu

Eli Lilly and Company, Indianapolis, USA

\section{OBJECTIVE}

To assess the effect of dulaglutide versus insulin glargine on elderly patients (aged $\geq 65$ years) with type 2 diabetes in achieving a composite endpoint of HbA1c goal without hypoglycemia at 52 weeks

\section{STUDY DESIGN}

- Post hoc analysis of elderly and nonelderly subgroups based on age $(\geq 65,<65$ years) who participated in the AWARD-2 trial, the study design of which has been previously published ${ }^{1}$ and is illustrated below

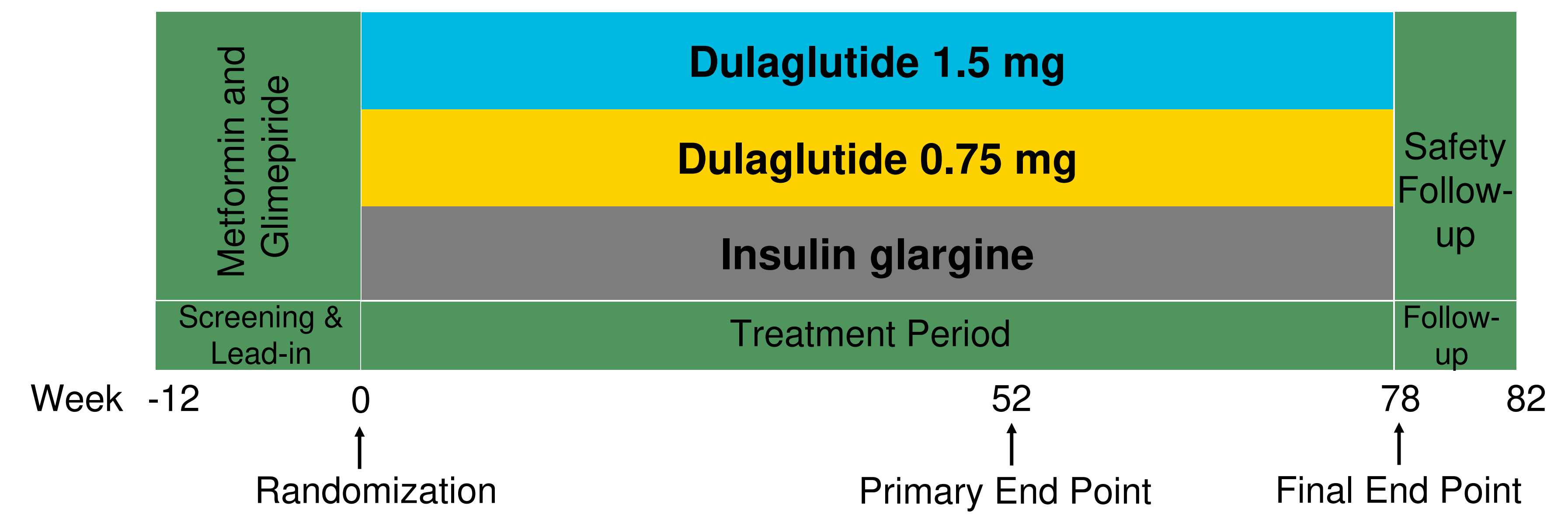

- The following composite endpoints were calculated at Week 52:

$-\mathrm{HbA} 1 \mathrm{c}<7.5 \%(58 \mathrm{mmol} / \mathrm{mol})$

- without documented symptomatic hypoglycemia ${ }^{1, a}$

- without nocturnal hypoglycemiab

$-\mathrm{HbA} 1 \mathrm{c}<8.0 \%(64 \mathrm{mmol} / \mathrm{mol})$

- without documented symptomatic hypoglycemia ${ }^{1, a}$

- without nocturnal hypoglycemiab

- An HbA1c goal of $<7.5 \%$ (58 $\mathrm{mmol} / \mathrm{mol})$ or $<8.0 \%(64 \mathrm{mmol} / \mathrm{mol})$ and a hypoglycemia definition of $\leq 70 \mathrm{mg} / \mathrm{dL}(3.9 \mathrm{mmol} / \mathrm{L})$ were chosen as targets appropriate for the elderly population ${ }^{2}$

- Analyses were carried out using counts, percentages, and logistic regression with pooled country, baseline $\mathrm{HbA1c}$ strata, treatment, age subgroup, and subgroup by treatment interaction

a Any time a patient feels that he or she is experiencing symptoms and/or signs associated with
hypoglycemia, and has a plasma glucose level of $\leq 70 \mathrm{mg} / \mathrm{dL}(3.9 \mathrm{mmol} / \mathrm{L})$.

${ }^{b}$ Any hypoglycemic event that occurred between bedtime and waking.

\section{KEY RESULT}

Higher \% of Dulaglutide-Treated Elderly Patients Achieved HbA1c $<7.5 \%$ Without Nocturnal Hypoglycemia at Week 52

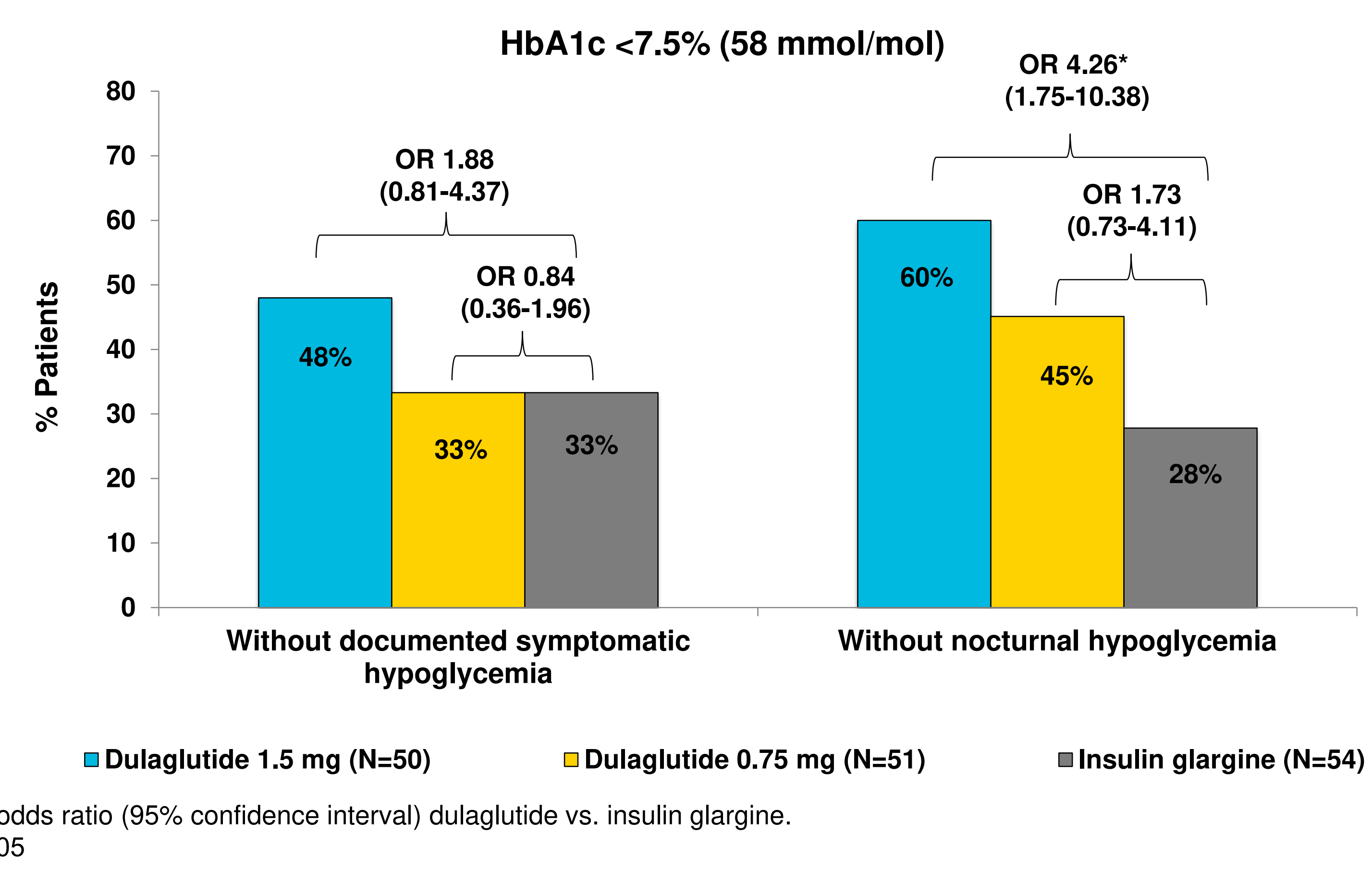

\section{CONCLUSION}

In this post hoc analysis of AWARD-2 (head-to-head study of dulaglutide versus insulin glargine), for elderly patients:

There was no significant difference between the groups in achieving target HbA1c $(<7.5 \%$ or $<8.0 \%$ [ $58 \mathrm{mmol} / \mathrm{mol}$ or 64 $\mathrm{mmol} / \mathrm{mol}]$ ) without documented symptomatic hypoglycemia However, significantly more patients on dulaglutide $1.5 \mathrm{mg}$ than on insulin glargine achieved target $\mathrm{HbA1c}$ without nocturnal hypoglycemia

\section{BASELINE CHARACTERISTICS}

\begin{tabular}{|l|c|}
\hline Characteristic & $\begin{array}{c}\text { Elderly Patients } \\
\mathbf{N}=161\end{array}$ \\
\hline Male, $\mathbf{n}(\%)$ & $90(56)$ \\
\hline Age, mean (SD) years & $69.3(3.7)$ \\
\hline Weight, mean (SD) kg & $83.6(15.4)$ \\
\hline Diabetes duration, mean (SD) years & $13.3(7.6)$ \\
\hline HbA1c & \\
\hline \multicolumn{1}{|c}{$\%$, mean (SD) } & $8.1(1.0)$ \\
\hline \multicolumn{1}{|c|}{ mmol/mol, mean } & 65 \\
\hline
\end{tabular}

\section{ADDITIONAL RESULTS}

Higher \% of Dulaglutide-Treated Elderly Patients Achieved HbA1c $<8.0 \%$ Without Nocturnal Hypoglycemia at Week 52

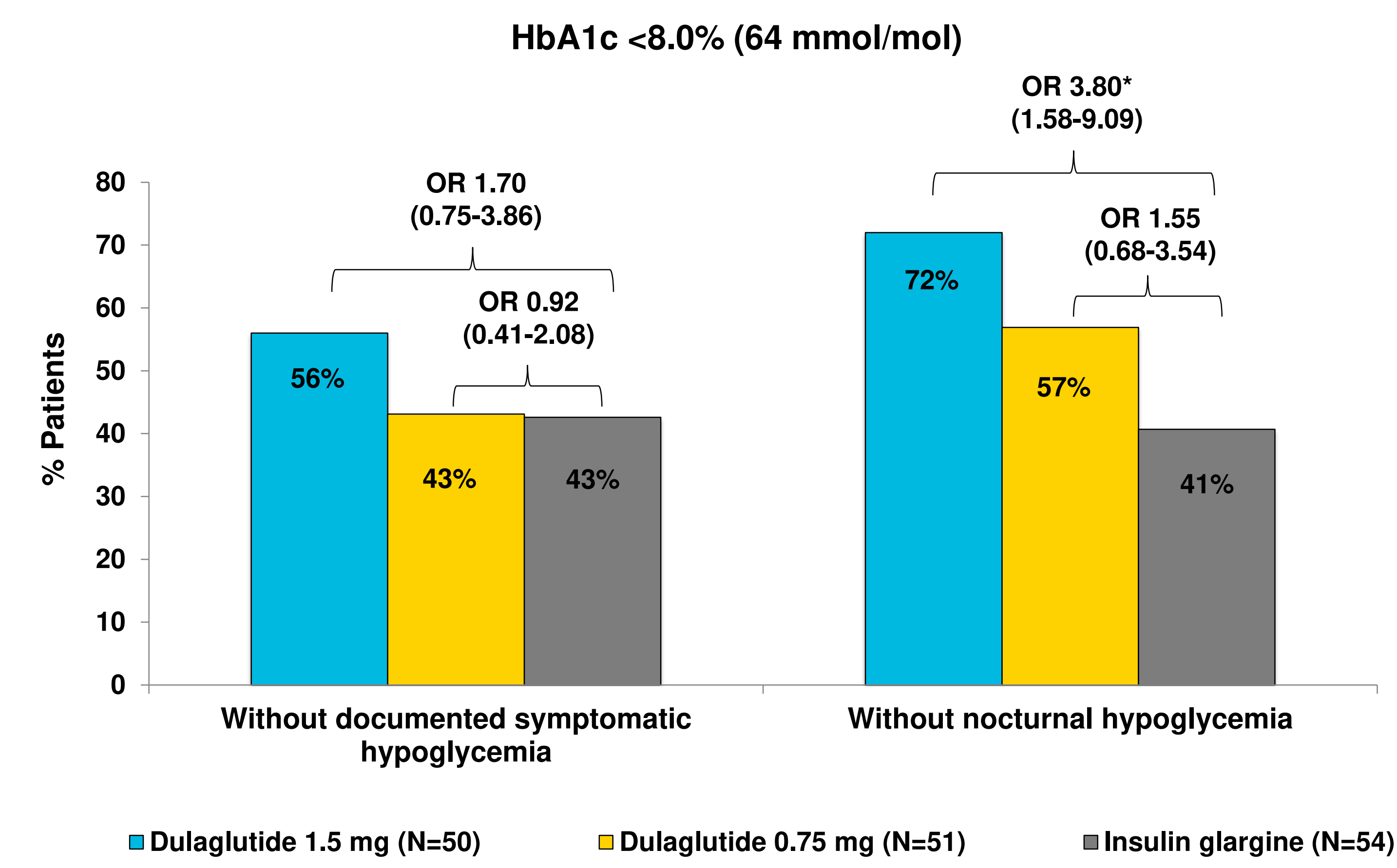

OR=odds ratio $(95 \%$ confidence interval) dulaglutide vs. insulin glargine.
$* \mathrm{p} \leq .05$

\% Elderly Patients Who Achieved Individual Components of the Composite Endpoints at Week 52

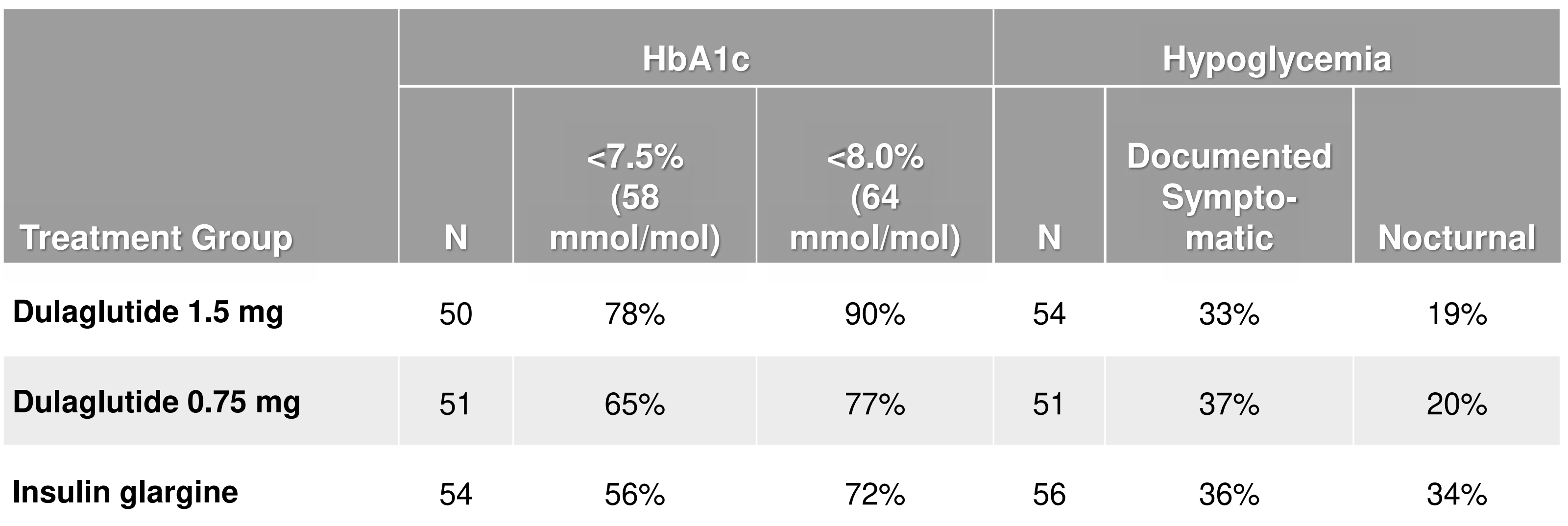

- No elderly patient in any treatment group reported severe hypoglycemia ${ }^{a}$

a An episode requiring the assistance of another person to actively administer carbohydrate, glucagon, or other resuscitative actions.

\section{Limitations}

This was a post hoc analysis with a limited sample size for the elderly subgroup (elderly in the AWARD-2 study, $n=161$; total AWARD-2 study population, $n=807$ )

\section{Acknowledgements}

The authors would like to thank Cindy C. Taylor at Synchrogenix, a Certara company, for medical writing support.

\section{References}

1. Giorgino F et al. Diabetes Care. 2015;38(12):2241-2249.

2. American Diabetes Association. 11.Older Adults. Diabetes Care. 2017;40(Suppl. 1):S99-S104. 